\title{
Portomesenteric air from acute necrotizing appendicitis
}

\author{
Jeffrey S. Lubin
}

Received: 2 January 2009 / Accepted: 18 January 2009 / Published online: 24 February 2009

(C) Springer-Verlag London Ltd 2009

A 75-year-old man presented to the emergency department (ED) with a history of 2 days of abdominal distention. He complained of mild nausea with vomiting but no abdominal pain or reported fevers. His temperature was $94.8^{\circ} \mathrm{F}\left(34.9^{\circ} \mathrm{C}\right)$, pulse was 106, and blood pressure was 99/59. He was awake and alert and did not appear toxic. His abdomen was firm and distended without significant tenderness. Initial laboratory tests, including white blood cell count, were essentially normal.

Figure 1 shows branching lucencies in the liver, suggesting either pneumobilia or portomesenteric venous gas. The presence of air in the left lobe of the liver extending beyond $2 \mathrm{~cm}$ from the liver capsule, as seen in the abdominal computed tomography (CT) scan shown in Fig. 2, confirms mesenteric and portal venous gas. This feature differs from pneumobilia, which is centrally located. His CT scan also demonstrated extensive pneumatosis involving the esophagus, stomach, and large portions of the bowel. The patient received broad-spectrum antibiotics in the ED and the general surgery department was consulted. His condition rapidly deteriorated, and he was resuscitated from cardiac arrest twice but ultimately died. Autopsy revealed acute necrotizing appendicitis, which led to sepsis and resulted in his death.

Morbidity and mortality in elderly patients with appendicitis ranges as high as $70 \%$ versus approximately $1 \%$ in the general population [1]. It is a difficult diagnosis to make since more than one half of elderly patients do not present with fever or leukocytosis. In addition, approximately one third do not localize pain to the right lower quadrant and one quarter do not have appreciable right lower quadrant tenderness. Portomesenteric gas is rare, but is often associated with fatal outcome [2].

\section{References}

1. Storm-Dickerson TL, Horattas MC (2003) What have we learned over the past 20 years about appendicitis in the elderly? Am J Surg 185(3):198-201

2. Sebastià C, Quiroga S, Espin E, Boyé R, Alvarez-Castells A, Armengol M (2000) Portomesenteric vein gas: pathologic mechanisms, CT findings, and prognosis. Radiographics 20(5):1213-1224

The views expressed in this paper are those of the author(s) and not those of the editors, editorial board or publisher.

J. S. Lubin $(\bowtie)$

Department of Emergency Medicine,

University Hospitals Case Medical Center,

Case Western Reserve University School of Medicine,

11100 Euclid Ave, Bolwell 3700,

Cleveland, OH 44106, USA

e-mail: Jeffrey.Lubin@uhhospitals.org 


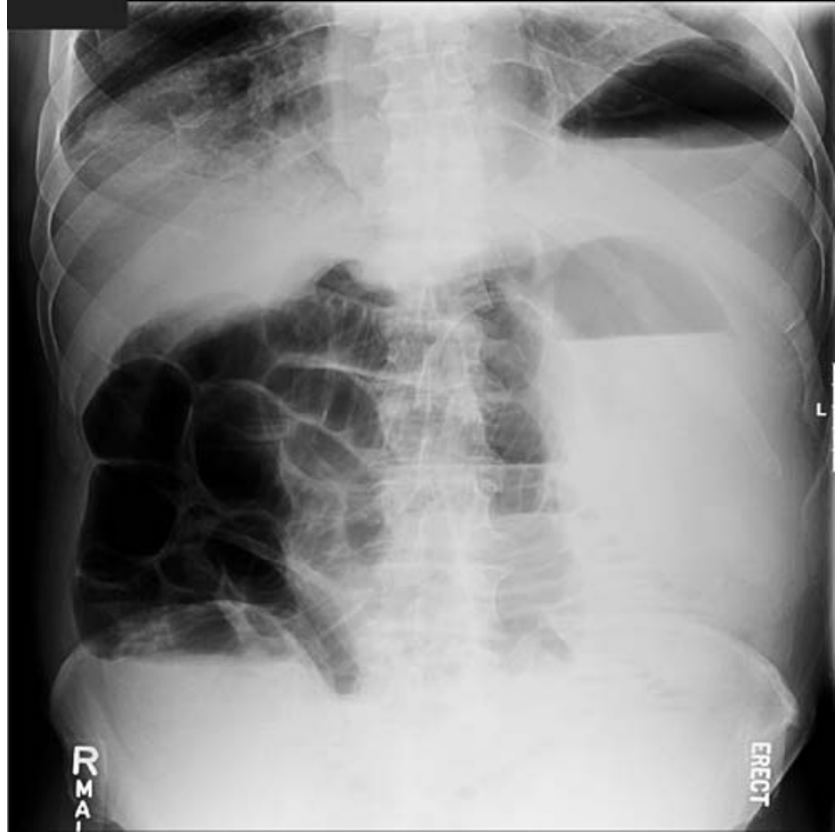

Fig. 1 Visualization of branching lucencies in the liver

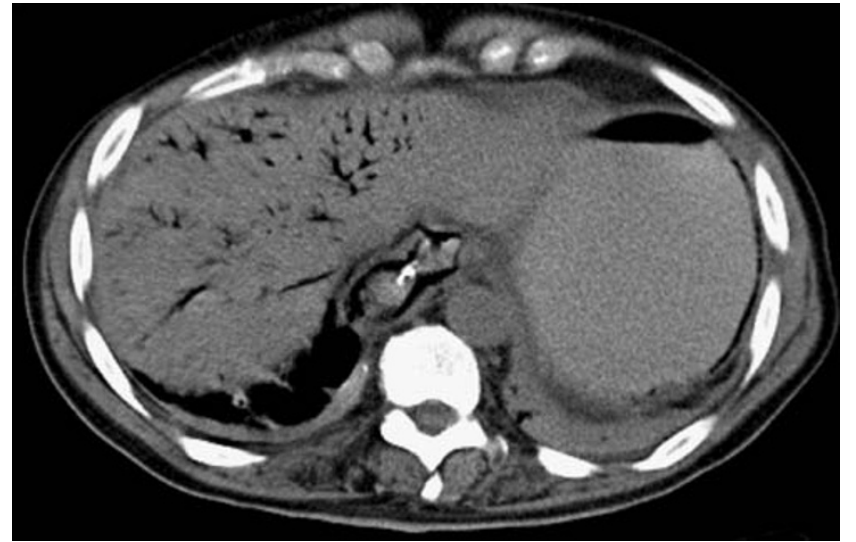

Fig. 2 CT scan demonstrating the presence of air in the left lobe of the liver extending beyond $2 \mathrm{~cm}$ from the liver capsule 